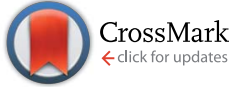

Received 27th October 2016 Accepted 28th November 2016

DOI: $10.1039 / c 6 r a 25938 c$

www.rsc.org/advances
Cite this: RSC Adv., 2017, 7, 2365

\section{An electrochemical cytosensor for ultrasensitive detection of cancer cells using modified graphene- gold nanostructures $\uparrow$}

\author{
Amir Yadegari, ${ }^{\text {ad }}$ Meisam Omidi, ${ }^{* b}$ Fatemeh Yazdian, ${ }^{c}$ Hakimeh ali $^{a}$ \\ and Lobat Tayebide
}

\begin{abstract}
The ultrasensitive detection of human prostate metastatic cancer cells (Du-145) was investigated through a novel electrochemical cytosensor. The proposed biosensor was simultaneously developed via two approaches: multivalent identification and signal amplification. Herein, anti-CD166 monoclonal antibody-modified gold electrode was applied to capture and recognize target cells (Du-145). Also, a graphene (G)/gold nanoparticle (GNP)/horseradish peroxidase (HRP)-conjugated trastuzumab antibody (G/GNP/Ab-HRP) hybrid nanostructure was designed as a nanoprobe for accurate recognition of target cells and efficient amplification of enzymatic signals simultaneously. The performance of the cytosensor could be significantly improved by utilizing this novel signal-amplification strategy. The cytosensor described here exhibited an appropriate cell-capture ability, broad range of detection, and exceptional sensitivity with a low limit of detection (20 cells). The fabricated cytosensor showed high sensitivity and selectivity for detection of Du-145 cancer cells while keeping an extended linear range from $10^{2}$ to $10^{6}$ cells per $\mathrm{ml}$, and a conveniently low limit of detection of 20 cells per $\mathrm{ml}$. The extraordinary analytical performance of this cytosensor indicates that it has a great potential for the detection of cancer cells and cancer stem cells.
\end{abstract}

\section{Introduction}

Developing highly sensitive nanobiosensors for the detection of bacteria, fungal pathogens, viruses, and cancer cells is essential in biomedical, clinical, and food-industry applications. ${ }^{\mathbf{1 , 2}} \mathrm{A}$ rapid and sensitive approach for early detection or diagnosis of cancer is absolutely crucial for more effective therapy. In particular, detection of metastatic cancer cells is one of the critical steps in cancer diagnosis. Hence, introducing a simple strategy for this intention is very important. ${ }^{3}$ While the techniques available for detection of cancer cells have their own benefits and drawbacks, the absence of developing an unsophisticated, inexpensive, rapid and sensitive procedure for cell detection is tangible. Electrochemical cytosensing methods play an important part in cell detection because of inherent

${ }^{a}$ Department of Tissue Engineering and Regenerative Medicine, School of Advanced Technologies in Medicine, Shahid Beheshti University of Medical Sciences, Tehran, Iran

${ }^{b}$ Protein Research Centre, Shahid Beheshti University, GC, Velenjak, Tehran, Iran. E-mail:m_omidi@sbmu.ac.ir

${ }^{c}$ Faculty of New Science and Technology, University of Tehran, Tehran, Iran

${ }^{d}$ Department of Developmental Sciences, Marquette University School of Dentistry, Milwaukee, WI 53233, USA

${ }^{e}$ Department of Engineering Science, University of Oxford, Oxford OX1 3PJ, UK

$\dagger$ Electronic supplementary information (ESI) available. See DOI: $10.1039 / \mathrm{c} 6 \mathrm{ra} 25938 \mathrm{c}$ advantages such as rapid response, miniaturization, affordability, and easy operation. ${ }^{4-7}$ Recently, electrochemical techniques such as differential pulse voltammetry (DPV), ${ }^{8-11}$ cyclic voltammetry (CV), ${ }^{12}$ stripping voltammetry (SV) ${ }^{\mathbf{1 3 , 1 4}}$ and electrochemical luminescence (ECL) ${ }^{\mathbf{1 5 , 1 6}}$ have been used for detection of cell number and type. However, the low selectivity and sensitivity of these electrochemical techniques may hinder their potential application. To improve the sensitivity of detection in electrochemical methods, electrocatalysts for signal amplification have been proposed. ${ }^{8}$ Signal amplification based on enzymatic reactions is one of the most prevalent approaches used in electrochemical cytosensors for improving sensitivity. ${ }^{9}$ Although significant progress has been made to improve the sensitivity of electrochemical biosensors, they still suffer from low sensitivity in comparison with other cell-sensing approaches. For instance, Gehring et al. reported the electrochemical detection of Salmonella typhimurium cells through capture of magnetic beadconjugated antibodies. ${ }^{17}$ Briefly, they deposited magnetic beads on a graphite electrode and employed an alkalinephosphataselabelled goat anti-Salmonella antibody to catalyse the production of para-aminophenol from the substrate. The produced para-aminophenyl phosphate was electrothermally detected, and the number of captured cells was proportioned to the generated signal with a sensitivity of $8 \times 10^{3}$ cells per ml. Similarly, Radke et al. designed an electrochemical-based impedimetric platform for detection of Escherichia coli bacteria with a sensitivity of $10^{4}$ to 
$10^{7} \mathrm{cfu} \mathrm{ml}^{-1}$ using goat anti-IgG antibody. ${ }^{18}$ Dill et al. developed light-addressable potentiometric sensors for high-accuracy detection of S. typhimurium (119 cfu). They utilized fluoresceinlabelled anti-Salmonella antibodies and biotinylated antibodies as the recognition biomarker for highly sensitive monitoring of Salmonella cells. $^{19}$ Hnaiein et al. fabricated a conductimetric immunosensor for high-accuracy detection of $E$. coli through capture of a biotinylated polyclonal antibody on magnetic nanoparticles. ${ }^{20}$ The conjugation of biomarkers on the conductimetric electrode was completed using glutaraldehyde. The magnetic nanoparticles could increase conductivity and facilitate the highly sensitive detection of $S$. epidermis cells $\left(0.5 \mathrm{cfu} \mathrm{ml}^{-1}\right)$. Nevertheless, selectivity is still a major problem for developing highaccuracy immunosensors, so a more selective and sensitive electrochemical cytosensor needs to be developed for detection of cancer cells. ${ }^{21}$ In the last decade, graphene (G) and its derivatives have been widely used for fabrication of different types of sensors, ${ }^{22,23}$ biosensors, ${ }^{24}$ and cytosensors ${ }^{25}$ due to their excellent properties. Sharma et al. reported an electrochemical preparation of a functionalized G-graphene-oxide (GO) nanocomposite electrode as a highly sensitive immunosensor. They believed that the functionalized GO noticeably improved the electrical properties of the nanocomposite due to high conductivity of $\mathrm{G}$ sheets. The results showed that the presence of $\mathrm{G}$ sheets significantly amplified the electrochemical signals for detection of diuron. ${ }^{26}$ Also, the immobilization and hybridization of GO with metallic nanoparticles have been suggested as an appropriate candidate for cancer cells detection because it can enhance the rate of electron transfer and amplification of electrochemical signals. ${ }^{27}$ In particular, gold nanoparticles (GNPs) show excellent biocompatibility, poor adsorption of biomolecules, high conductivity, and high catalytic behavior towards electrochemical reactions. Thus, combination of GNPs with $\mathrm{G}$ sheets significantly improves the rate of electron transfer between biomarkers and the electrode surface by increasing the rate of electrochemical reactions. ${ }^{28}$ Huang et al. designed a sensitive label-free amperometric immunosensor based on the hybridization of functionalized G and GNPs. The fabricated immunosensor was immobilized with $\alpha$-fetoprotein antibody (anti-AFP) for detection of $\alpha$-fetoprotein. The results showed that the combination of G sheets and GNPs considerably improved sensitivity, long-term bioactivity and stability of the immunosensor owing to high electron transfer, large surface area, and appropriate electrostatic adsorption..$^{29}$ In the present study, a novel electrochemical cytosensor working upon multivalent recognition and signal amplification was developed for ultrasensitive detection of human prostate cancer cells (Du-145). Du-145 is a cell line of prostatic cancer with metastatic potential. ${ }^{30}$ Immunohistologic studies have revealed overexpression of cluster of differentiation $166(\mathrm{CD} 166)^{31}$ and human epidermal growth factor receptor 2 (HER2) $^{32}$ in Du-145 cells. Herein, an anti-CD166 antibody-modified gold electrode was used to capture and recognize target cells (Du-145). Also, a G/GNP/horseradish peroxidase (HRP) conjugated anti-HER2 antibody (G/GNP/Ab-HRP) hybrid nanostructure was designed as a nanoprobe for accurate recognition of target cells and efficient amplification of enzymatic signals. The electrochemical cytosensor that we developed exhibited a unique performance for the detection of cancer cells.

\section{Experimental}

\subsection{Chemicals and materials}

All chemical materials and reagents in this study were supplied from Sigma-Aldrich (Saint Louis, MO, USA). GO was prepared according to our previous work. ${ }^{33}$ All chemical materials and reagents were used in their initial form without further purification or manipulation. HRP-HER2 and CD166 monoclonal antibody were purchased from Abcam (Cambridge, MA, USA). Deionized water (DI) with a resistivity of $\sim 18 \mathrm{M} \Omega$ cm was achieved using a Millipore (Bedford, MA, USA) system and used throughout all experiments. 293T, L02, HepG2 and MCF-7 lines were purchased from American Type Culture Collection (Manassas, VA, USA).

\subsection{Synthesis of gold/reduced GO composite}

GNPs were decorated on GO sheets through direct chemical reduction of chloroauric acid $\left(\mathrm{HAuCl}_{4}\right)$ by sodium borohydride $\left(\mathrm{NaBH}_{4}\right)$. Briefly, $200 \mu \mathrm{l}$ of $\mathrm{HAuCl}_{4}(0.02 \mathrm{M})$ was gradually added to GO solution $\left(1 \mathrm{mg} \mathrm{ml}^{-1}\right)$ and the mixture was stirred for $2 \mathrm{~h}$ at room temperature. Then, $0.1 \mathrm{ml}(0.1 \mathrm{M}) \mathrm{NaBH}_{4}$ was gently poured into the mixture and stirring maintained for $1 \mathrm{~h}$ at room temperature. Finally, the obtained sample was repeatedly washed with DI water thrice.

\subsection{Preparation of G/GNP/Ab-HRP nanoprobes}

G/GNP/Ab-HRP nanoprobes were achieved by introducing 3-mercaptopropionic acid (3MPA) to G/GNP (Scheme 1a). Typically, $2.5 \mathrm{ml}$ 3MPA solution in phosphate-buffered saline (PBS; $0.1 \mathrm{mM}, \mathrm{pH}=7$, with $0.1 \mathrm{mg} \mathrm{ml}^{-1}$ Tween 20) was added to $2.5 \mathrm{ml} \mathrm{G} / \mathrm{GNP}\left(1 \mathrm{mg} \mathrm{ml}^{-1}\right)$ and the mixture was stirred for $5 \mathrm{~h}$ at room temperature. Subsequently, the obtained mixture was centrifuged and repeatedly washed with PBS to remove excess reagent. Afterwards, 3MPA-modified G/GNP was incubated with $100 \mathrm{mM}$ 1-ethyl-3-(3-dimethylaminopropyl) carbodiimide and $N$-hydroxysuccinimide (EDC/NHS) for $10 \mathrm{~min}$. Meanwhile, $0.4 \mathrm{mg} \mathrm{ml}^{-1}$ monoclonal HRP-HER2 antibody was injected into the mixture and maintained in $4{ }^{\circ} \mathrm{C}$ under an inert atmosphere for $2 \mathrm{~h}$. The resulting G/GNP/Ab-HRP nanoprobes were collected and washed by centrifugation, and finally re-dispersed in PBS $(0.1 \mathrm{mM}, \mathrm{pH}=7$, with $0.1 \mathrm{mg}$ $\mathrm{ml}^{-1}$ Tween 20).

\subsection{Cell culture}

Human prostate cancer cell line Du-145 was obtained from American Type Culture Collection. Cells were maintained in RPMI 1640 supplemented with 10\% fetal bovine serum, $100 \mathrm{IU}$ $\mathrm{ml}^{-1}$ penicillin, and $100 \mu \mathrm{g} \mathrm{ml} \mathrm{g}^{-1}$ streptomycin at $37^{\circ} \mathrm{C}$ and $5 \%$ $\mathrm{CO}_{2}$. Trypsinization was used to obtain cell suspensions and a blood counting chamber was applied for determination of cell number.

\subsection{Flow cytometry}

Flow cytometry was employed to consider the formation of binding between Du-145 cells and nanoprobes. In a typical 

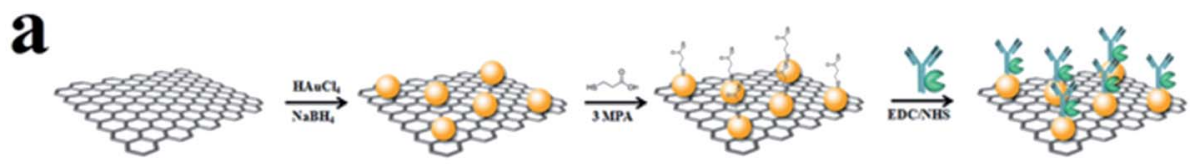

b
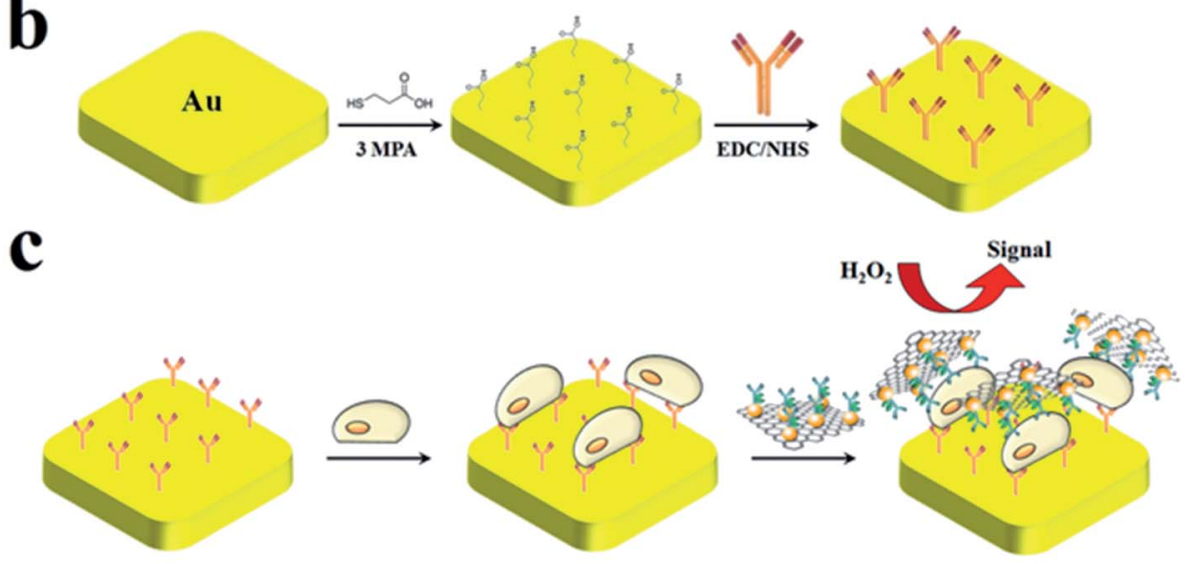

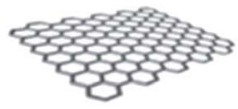

Graphene

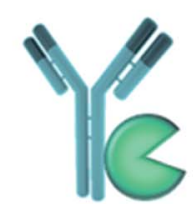

HRP- HER2 Ab

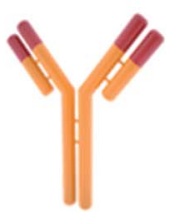

CD166 Ab

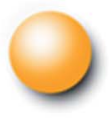

GNP

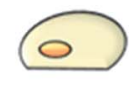

Cancer Cell

Scheme 1 (a) Procedures for the fabrication of a G/GNP/Ab-HRP nanoprobe. (b) Procedure for preparing the electrochemical cytosensor. (c) Schematic illustration of the novel electrochemical cytosensor for detection of cancer cells.

experiment, G/GNP and G/GNP/Ab-HRP nanoprobes were labeled with fluorescein isothiocyanate. Subsequently, $10 \mu \mathrm{l}$ of the labeled nanoprobes were incubated with Du-145 cells for $1 \mathrm{~h} \cdot{ }^{34}$ After that, cells were thoroughly washed with PBS. Finally, they were trypsinized and analyzed using a flow cytometry system (Sysmex Partec, Görlitz, Germany).

\subsection{Cytosensor fabrication}

First, a gold working electrode (diameter, $2 \mathrm{~mm}$ ) was polished with alumina slurry $(0.3 \mu \mathrm{m})$ to obtain a mirror-like surface. Afterwards, the electrode was successively immersed in ethanol, acetone, piranha solution $\left(\mathrm{H}_{2} \mathrm{SO}_{4} / \mathrm{H}_{2} \mathrm{O}_{2}=1: 1\right)$ and DI water and sonicated for $3 \mathrm{~min}$ in each solution. The clean electrode was immediately immersed in 3MPA solution $(0.5 \mathrm{mM}, \mathrm{pH}=$ 11) for $2 \mathrm{~h}$ at room temperature. Subsequently, the 3MPAmodified electrode was washed with DI water and immersed in $0.1 \mathrm{mg} \mathrm{ml}^{-1} \mathrm{CD} 166$ antibody solution in the presence of EDC/ NHS (100 mM) for $24 \mathrm{~h}$ under an inert atmosphere. Afterwards, the CD166-modified electrode was washed with DI water to remove excess reagent (Scheme 1b). Then, the electrode was immersed in different concentrations of cell suspension for $1 \mathrm{~h}$ at $37^{\circ} \mathrm{C}$. The resulting Du- 145 cell/antibody/gold electrode was washed and incubated with G/GNP/Ab-HRP nanoprobes for $1 \mathrm{~h}$. Eventually, the modified electrode was used for subsequent electrochemical measurements (Scheme 1c).

\subsection{Characterization}

Electrochemical measurements were carried out using an electrochemical interface and impedance analyzer (IVIUMSTAT.XR; Ivium Technologies, Eindhoven, the Netherlands). The morphology of samples was thoroughly investigated by transmission electron microscopy (TEM; EM208 transmission electron microscope; Philips, Amsterdam, the Netherlands) and atomic force microscopy (AFM; 0201/A atomic force microscope; Ara Research, Tehran, Iran). Ultraviolet-Visible (UV-Vis) spectra measurements were carried out on an AvaSpec 2048TEC spectrophotometer (Avantes, Apeldoorn, the Netherlands). X-ray diffraction (XRD) spectroscopy was performed with a step size of $0.02(2 \theta) / \mathrm{s}$ with $\mathrm{Cu} \mathrm{K} \alpha$ radiation using an X'Pert PRO MPD diffractometer (PANalytical, Almelo, the Netherlands).

\section{Results and discussion}

\subsection{Working principle of the electrochemical cytosensor}

The electrochemical cytosensor based on a signal-amplification and dual-recognition strategy is presented in Scheme 1. The gold/reduced GO composite was prepared first owing to its catalytic properties and excellent biocompatibility. The nanoprobes were fabricated by introducing HRP-HER2 antibody to G/GNP (Scheme 1a). Then, CD166 antibody was attached to the surface of the working electrode for cell capture (Scheme 1b). Afterwards, the resulting cell/antibody/gold electrode was 
incubated with G/GNP/Ab-HRP nanoprobes to form a "sandwichlike" system. Due to the specific recognition and high binding affinity of the antibody, the sandwich-like system could be exclusively formed in the presence of the target cells (Scheme 1c). Electrochemical signals can be enhanced by hydroquinone (HQ), which is generated by the enzymatic reaction of HRP in the presence of hydrogen peroxide $\left(\mathrm{H}_{2} \mathrm{O}_{2}\right)$. The electrochemical signals (DPV peaks) are directly related to the enzymatic reaction of HRP present on the electrode surface. As a result, the number of captured target cells can be estimated. Because of loading of a large number of HRP-HER2 conjugates, as well as the specific recognition and high binding affinity of antibody, the selectivity and sensitivity of this cytosensor was greatly enhanced.

\subsection{Characterization of nanoprobes}

AFM and TEM images of the prepared GO are shown in Fig. 1A and $\mathrm{B}$, respectively. As can be observed, the pristine graphite sheets were thoroughly exfoliated into single-layer GO nanosheets. In addition, the thickness of the obtained GO nanosheets was found to be $\sim 2 \mathrm{~nm}$ by AFM. With regard to the lateral width of $\mathrm{G}$ sheets, the size distribution was estimated to be $100 \mathrm{~nm}$ to $800 \mathrm{~nm}$. Fig. 2C shows the TEM image of GNPs and GO composite: GNPs were uniformly deposited on the reduced GO sheets without obvious agglomeration. The average size of the deposited GNPs was found to be about $10 \pm 1 \mathrm{~nm}$. The XRD patterns of GO and G/GNP are shown in Fig. 1D. The distinctive peak at $2 \theta \sim 26.01^{\circ}$ is related to the (002) plane of graphite (curve a). As the XRD pattern of G/GNP clearly shows, the appearance of additional peaks at $2 \theta \sim 38.3,44.4,64.7$ and $77.7^{\circ}$ correspond to the (111), (200), (220) and (311) planes of the GNPs, respectively (curve b). ${ }^{35}$ The UV-Vis absorption spectra of GO, G/GNP and G/GNP/Ab-HRP are shown in Fig. 1E. GO showed two absorption peaks: a strong absorption peak at $\sim 230 \mathrm{~nm}$ and a shoulder at $\sim 300 \mathrm{~nm}$ corresponding to the
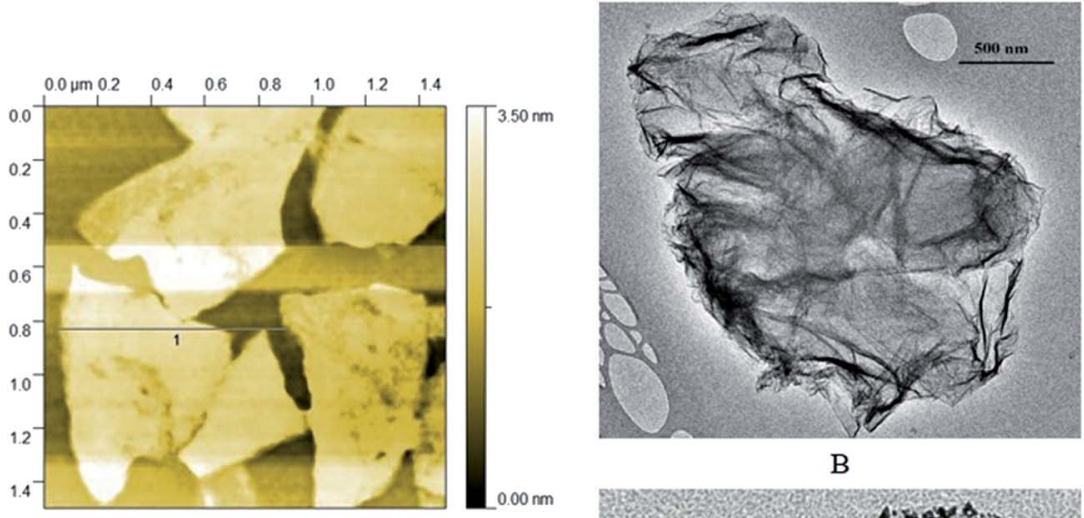

B

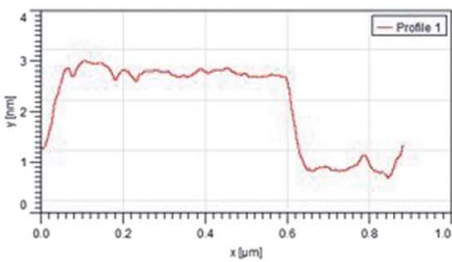

A

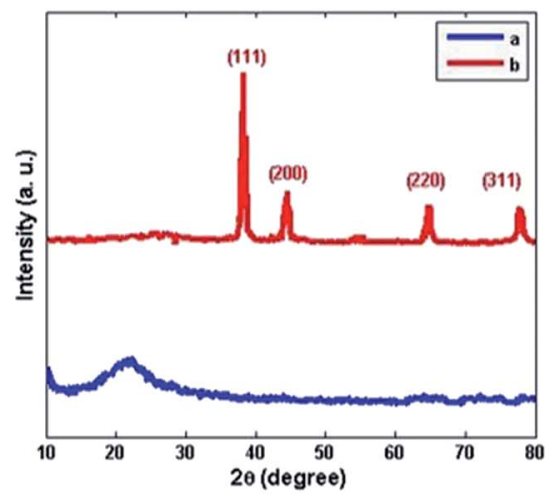

$\mathrm{D}$

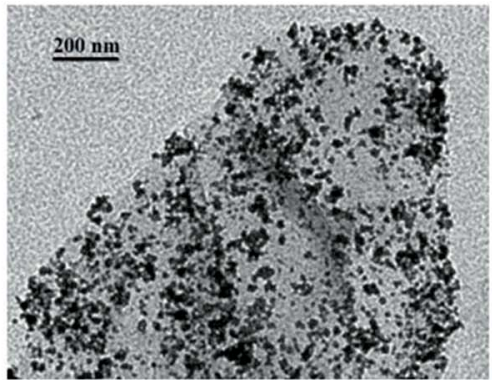

C

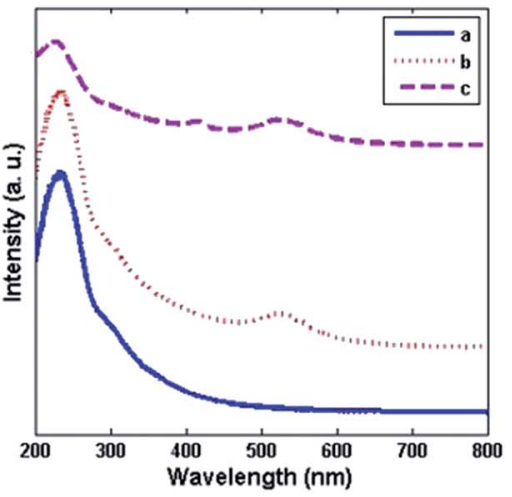

E

Fig. 1 (A) AFM image and height profiles of GO. (B and C) TEM images of (B) GO and (C) G/GNP. (D) XRD patterns of GO (a) and G/GNP (b). (E) UVvisible absorption spectrum of GO (a), G/GNP (b) and G/GNP/Ab-HRP (c). 


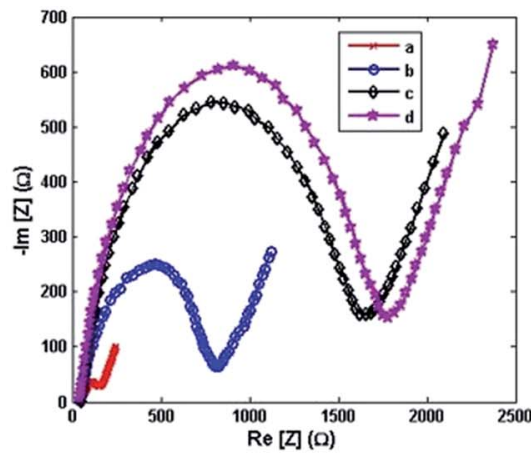

A

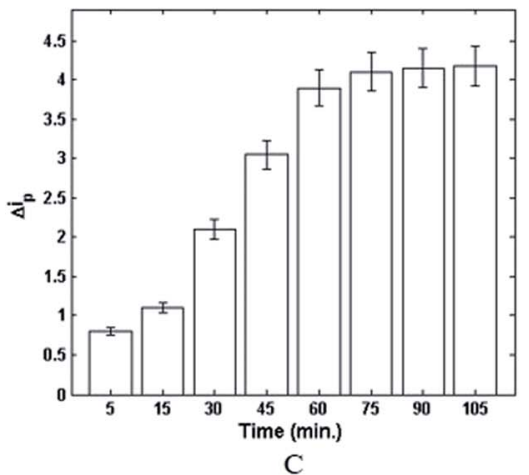

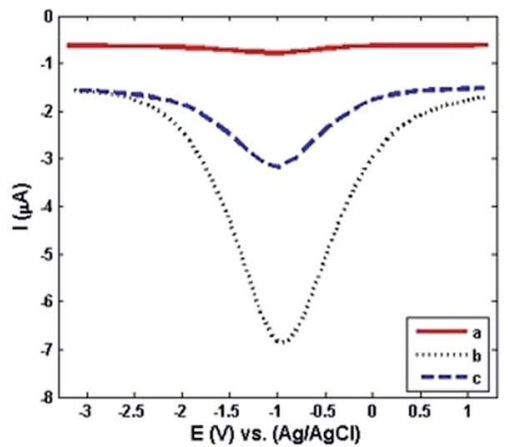

B

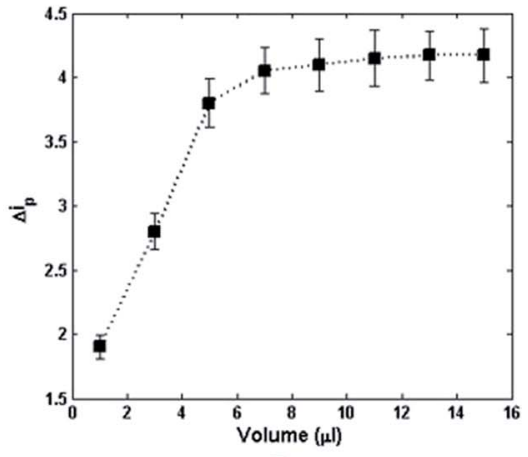

$\mathrm{D}$

Fig. 2 (A) Electrochemical impedance spectra of a bare gold electrode (a), CD166/gold electrode (b), Du-145 cell/CD166/gold electrode (c), and $\mathrm{G} / \mathrm{GNP} / \mathrm{Ab}-\mathrm{HRP} / \mathrm{Du}-145$ cell/CD166/gold electrode (d). All measurements were recorded in $0.1 \mathrm{M} \mathrm{KCl}$ solution containing $4 \mathrm{mM}\left[\mathrm{Fe}\left(\mathrm{CN}_{6}\right)\right]^{4-/ 3-}$. (B) DPV of G/GNP/Ab-HRP/Du-145 cell/CD166/gold electrode in an electrolyte of PBS solution (pH 7.0, 100 mM) (a) without, (b) with 1.5 mM $\mathrm{H}_{2} \mathrm{O}_{2}$, and (c) CD166/gold electrode after incubation in G/GNP/Ab-HRP nanoprobes without cells. (C and D) Effects of the (C) incubation time and (D) volume for G/GNP/Ab-HRP nanoprobes on the $\Delta i_{p}$ of the cytosensor

$\pi-\pi *$ transition of $\mathrm{C}=\mathrm{C}$ and $\mathrm{n}-\pi^{*}$ transitions of $\mathrm{C}=\mathrm{O}$, respectively (curve a). ${ }^{36} \mathrm{G} / \mathrm{GNP}$ showed a new band at $\sim 520 \mathrm{~nm}$ (curve b), which was ascribed to the LSPR peak of GNP. ${ }^{37}$ In addition, due to the partial reduction of GO, the absorption peaks at $\sim 230$ and $\sim 300 \mathrm{~nm}$ disappeared. The absorption spectra of G/ GNP/Ab-HRP showed a LSPR peak at $\sim 525 \mathrm{~nm}$ and low-intensity band at $\sim 410 \mathrm{~nm}$ (curve $\mathrm{c}$ ). These results confirmed that Ab-HRP was effectively conjugated onto G/GNP. In accordance with its excellent affinity, appropriate biocompatibility and large surface area, G/GNP was favored for increasing the loading of Ab-HRP, which improves amplification of enzymatic signals.

Flow cytometry was also employed to consider the formation of binding between Du-145 cells and nanoprobes. As presented in Fig. $\mathrm{S} 1, \uparrow$ the results of flow cytometry show that the connection between G/GNP and Du-145 cells was estimated to be $\sim 5 \%$ (Fig. $\mathrm{S} 1 \mathrm{~A} \dagger$ ); however, the connection between Du-145 cells and G/GNP/Ab-HRP was $>90 \%$ (Fig. S1B $\dagger$ ), indicating high affinity between Du-145 cells and the designed nanoprobes. The high affinity between Du-145 cells and G/GNP/AbHRP nanoprobes can be explained by the membrane overexpression of HER 2 on the surface of Du-145 cells that has been reported in many studies. ${ }^{32}$

\subsection{Electrochemical behavior of the biosensor}

The stepwise assembly processes of the modified electrode were confirmed by electrochemical impedance spectroscopy (EIS).
Fig. 2A shows the Nyquist plots of the gold electrode which was gradually modified step by step according to the Experimental section. A minuscule semicircle domain for the bare gold electrode was observed (curve a), implying a fast electron-transfer process. After that, CD166 was assembled on the gold electrode. A conspicuous escalation of the semicircle diameter was also observed (curve b), indicating a noticeable augmentation of electrochemical impedance. Moreover, the apparent increase in the resistance with sequential assembly of cancer cells (curve c) could be discerned. Eventually, as can be seen in Fig. 2A (curve d), increasing the electrochemical impedance after incubation of nanoprobes verified stepwise alteration in impedance. These results revealed accomplishment of an antibody-cell-nanoprobe sandwich-like architecture. Thus, EIS is an appropriate technique for highly sensitive detection of cancer cells. Apart from electrochemical impedance, DPV was employed as a supplementary technique for further investigation of the signal-amplification strategy. As shown in Fig. 2B, a very small and weak DPV current peak was observed when the G/GNP/AbHRP/Du-145 cell/CD166/gold electrode was placed in PBS (pH 7.0, $0.1 \mathrm{M}$ ) as an electrolyte (curve a). Whereas, by immersing the G/GNP/Ab-HRP/Du-145 cell/CD166/gold electrode in PBS in the presence of $1.5 \mathrm{mM} \mathrm{H}_{2} \mathrm{O}_{2}$, the intensification of the DPV current density was sharply increased (curve b). This phenomenon implies that the initiation of this reaction completely depends on the signal-catalysis of HRP in the presence of $\mathrm{H}_{2} \mathrm{O}_{2}$. 
The electrochemical characteristics of the proposed cytosensor were further examined in $100 \mathrm{mM}$ PBS containing $1.5 \mathrm{mM} \mathrm{H}_{2} \mathrm{O}_{2}$. The obvious reduction of current density (curve c) was due to the incubation of CD166/gold electrode with G/GNP/Ab-HRP nanoprobes in the absence of Du-145 cells. Also, the DPV signal was determined by the total number of G/GNP/Ab-HRP nanoprobes attached to captured cancer cells. Thus, it can be concluded that the nanoprobes have a pivotal role not only for amplification of current density, but also for increasing the sensitivity of detection of Du-145 cells. It was also found that recognition of the specific nanoprobes on targeted cells as well as capture of cells on the CD166-modified gold surface could be affected by incubation time. The alteration of peak current density $\left(\Delta i_{\mathrm{p}}\right)$ with incubation time is shown in Fig. $2 \mathrm{C}$. It can be seen that a minor increase in the incubation time led to a significant increase in $\Delta i_{\mathrm{p}}$. However, the current signal reached a plateau after 75 min even if a longer incubation time was employed. Therefore, the desired incubation time for cell capture and nanoprobe incubation was found to be $\sim 75 \mathrm{~min}$. In addition to the results mentioned above, the impact of the volume of nanoprobe solution was further investigated for the proposed cytosensor. Fig. 2D shows the relationship between $\Delta i_{\mathrm{p}}$ and the volume of nanoprobe solution. Accordingly, the intensity of peak current density linearly increased with increasing the volume of nanoprobe solution until it reached $\sim 7 \mu \mathrm{l}$. Then, from $7 \mu \mathrm{l}$ to $15 \mu \mathrm{l}$, the plot revealed that the intensity of peak current density was approximately independent from the volume of nanoprobe solution. With regard to this behavior, the optimum volume solution for the nanoprobe is estimated to be $\sim 7 \mu$ l for the designed cytosensor.

\subsection{Detection of target cells}

The responses of DPV and the linear calibration of $\Delta i_{\mathrm{p}}$ versus the concentration of Du-145 cells are illustrated in Fig. 3A and B. Fig. 3A shows that DPV responses increase with augmentation of the concentration of cancer cells. Fig. 3B exhibits an excellent linear relationship between $\Delta i_{\mathrm{p}}$ and the logarithmic concentration of the cancer cells ranging from $10^{2}$ cells per $\mathrm{ml}$ to $10^{6}$ cells per $\mathrm{ml}$. The related linear regression equation is $\Delta i_{\mathrm{p}}(\mu \mathrm{A})=$ $2.0652+1.1213 \log C$ cells (cells per $\mathrm{ml}$ ) with a correlation coefficient of $0.96(n=5)$. Limit of detection (LOD) is defined as the lowest possible concentration of analyte which can be distinguished without any assurance about the imprecision of the obtained results. Herein, LOD was calculated from the following equation: ${ }^{37}$

$$
\mathrm{LOD}=3 \sigma / b
$$

where $b$ is the sensitivity of the cytosensor (slope of the regression line) and $\sigma$ is the standard deviation of blank.

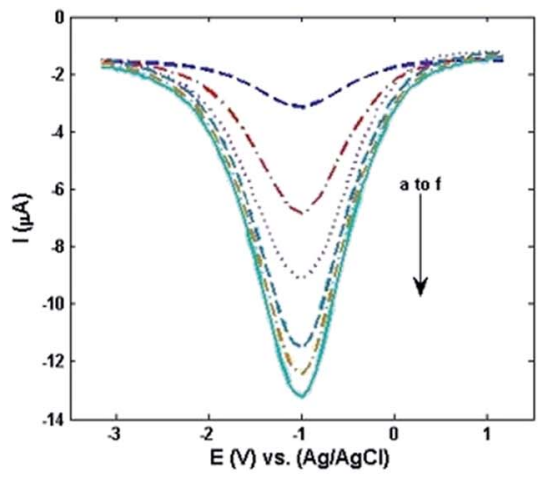

A

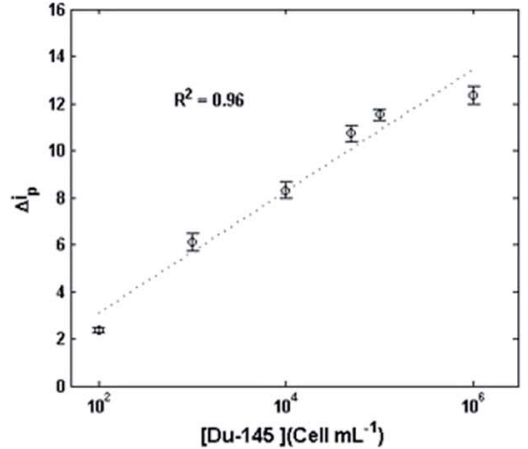

B

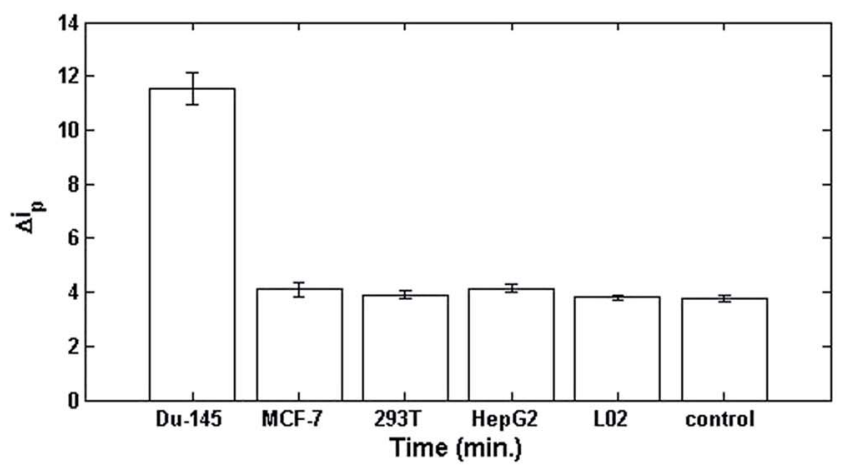

$\mathrm{C}$

Fig. 3 (A) DPV responses to different concentrations of Du-145 cells (from (a) to (f): $10^{2}, 10^{3}, 10^{4}, 5 \times 10^{4}, 10^{5}$ and $10^{6}$ cells per ml) and (B) plot of $\Delta i_{\mathrm{p}} v$ s. the logarithmic values of the Du-145 cells concentration. (C) Peak current responses of the cytosensor to various types of cells at the concentration of $10^{5}$ cells per $\mathrm{ml}$. All measurements were recorded from -0.3 to $0.1 \mathrm{~V}$ in $100 \mathrm{mM} \mathrm{PBS}$ buffer (pH 7.0) containing $1.5 \mathrm{mM} \mathrm{H} \mathrm{O}_{2}$. The error bars represent relative signals across three repetitive experiments. 
Table 1 Comparison of the presented cytosensor and other reported biosensors for detection of cancer cells

\begin{tabular}{llll}
\hline Detection method & Cell line & $\begin{array}{l}\text { Detection limit } \\
\text { (cells per ml) }\end{array}$ & $\begin{array}{l}\text { Linear range } \\
\text { (cells per ml) }\end{array}$ \\
\hline DPV $^{9}$ & Hela & 300 & $3 \times 10^{2}$ to $10^{7}$ \\
DPV $^{8}$ & CCRF-CEM & 10 & $10^{2}$ to $5 \times 10^{4}$ \\
CV $^{10}$ & MCF-7 & 100 & $10^{2}$ to $10^{7}$ \\
EIS $^{3}$ & Hela & 500 & $5 \times 10^{2}$ to $5 \times 10^{6}$ \\
DPV (this work) & Du-145 & 20 & $10^{2}$ to $10^{6}$
\end{tabular}

According to eqn (1) a LOD of 20 cells per $\mathrm{ml}$ was achieved for Du-145 cells. In a typical experiment, $150 \mu \mathrm{l}$ of cell suspension was selected for detection. Thus, the LOD of the designed cytosensor can be calculated by multiplying the volume of cell suspension $(150 \mu \mathrm{l})$ and the calculated LOD by the equation shown above ( 20 cells per $\mathrm{ml}$ ), which is $\sim 3$ cancer cells. It is obvious that the sensitivity was significantly lower than those electrochemical-based cytosensors which employed detection methods based on EIS, DPV, and CV (Table 1). The low LOD of our cytosensor can be attributed to the dual and simultaneous recognition of antibody and amplification of the enzymatic signal of HRP. To study the specificity and uniqueness of the proposed cytosensor, a series of detection experiments was performed using different types of cell lines, such as human breast cancer MCF-7 cells, human embryonic kidney 293T cells, human normal hepatocyte L02 cells, human liver hepatocellular carcinoma HepG2 cells, as well as a sample without cells (blank control). Fig. 3C shows that there was no significant alteration in DPV responses for MCF-7, 293T, HepG2 and L02 cells in comparison with the blank control. This astonishing performance shows an unprecedented selectivity and sensitivity of the designed cytosensor and great potential application for detection of cancer cells by the proposed strategy. At the concentration of $10^{3}$ cells per $\mathrm{ml}$, the designed electrochemical cytosensor exhibited a relative standard deviation of $2.9 \%$ for five determinations, implying convenient repeatability. All in all, the proposed electrochemical cytosensor revealed excellent selectivity, and repeatability.

\section{Conclusion}

In this study, an electrochemical-based cytosensor via a dual functionality (i.e., specific recognition and signal amplification for Du-145 human prostate cancer cells) was successfully developed. The proposed cytosensor demonstrated high sensitivity and selectivity toward Du-145 cancer cells, a conveniently low LOD of 20 cells per $\mathrm{ml}$ with decreasing repeatability, and an extended linear range from $10^{2}$ to $10^{6}$ cells per ml. Compared to cytosensors reported previously, the designed electrochemical biosensor showed remarkable performance for detection of cancer cells. Owing to the above-mentioned considerations, our electrochemical cytosensor is a significant development for detection of cancer cells, and has great potential for the early diagnosis of cancer. Nevertheless, this electrochemical-based biosensor is still in the development phase. Thus, many more comprehensive studies should be done to implement a sensitive and selective electrochemical approach for commercial laboratories and real-world medical and biomedical applications.

\section{Abbreviations}

$\begin{array}{ll}\text { AFM } & \text { Atomic force microscopy } \\ \text { GO } & \text { Graphene oxide } \\ \text { Du-145 } & \text { Human prostatic metastatic cancer cell } \\ \text { HRP } & \text { Horseradish peroxidase } \\ \text { LOD } & \text { Limit of detection } \\ \text { GNP } & \text { Gold nanoparticle } \\ \text { DPV } & \text { Differential pulse voltammetry } \\ \text { EIS } & \text { Electrochemical impedance spectroscopy } \\ \text { HQ } & \text { Hydroquinone } \\ \text { MCF-7 } & \text { Human breast cancer cell } \\ \text { 293T } & \text { Human embryonic kidney cell } \\ \text { L02 } & \text { Human normal hepatocyte cell } \\ \text { HepG2 } & \text { Human liver hepatocellular carcinoma } \\ \text { TEM } & \text { Transmission electron microscopy } \\ \text { XRD } & \text { X-ray diffraction } \\ \text { LSPR } & \text { Localized surface plasmon resonance }\end{array}$

\section{Acknowledgements}

This work was supported by the Shahid Beheshti University of Medical Sciences (Grant No. 7655).

\section{Notes and references}

1 T. K. Sharma, R. Ramanathan, R. Rakwal, G. K. Agrawal and V. Bansal, Proteomics, 2015, 15, 1680-1692.

2 B. Byrne, E. Stack, N. Gilmartin and R. O'Kennedy, Sensors, 2009, 9, 4407-4445.

3 M. Omidi, M. Malakoutian, M. Choolaei, F. Oroojalian, F. Haghiralsadat and F. Yazdian, Chin. Phys. Lett., 2013, 30, 068701.

4 J.-J. Zhang, M.-M. Gu, T.-T. Zheng and J.-J. Zhu, Anal. Chem., 2009, 81, 6641-6648.

5 T.-T. Zheng, R. Zhang, L. Zou and J.-J. Zhu, Analyst, 2012, 137, 1316-1318.

6 C. Hu, D.-P. Yang, Z. Wang, P. Huang, X. Wang, D. Chen, D. Cui, M. Yang and N. Jia, Biosens. Bioelectron., 2013, 41, 656-662.

7 S. Zhang, L. Zhang, X. Zhang, P. Yang and J. Cai, Analyst, 2014, 139, 3629-3635.

8 W. Cheng, L. Ding, J. Lei, S. Ding and H. Ju, Anal. Chem., 2008, 80, 3867-3872.

9 L. Ding, Q. Ji, R. Qian, W. Cheng and H. Ju, Anal. Chem., 2010, 82, 1292-1298.

10 X. Chen, Y. Wang, Y. Zhang, Z. Chen, Y. Liu, Z. Li and J. Li, Anal. Chem., 2014, 86, 4278-4286.

11 X. Wang, J. Ju, J. Li, J. Li, Q. Qian, C. Mao and J. Shen, Electrochim. Acta, 2014, 123, 511-517.

12 X. Zhu, J. Yang, M. Liu, Y. Wu, Z. Shen and G. Li, Anal. Chim. Acta, 2013, 764, 59-63. 
13 L. Ding, W. Cheng, X. Wang, S. Ding and H. Ju, J. Am. Chem. Soc., 2008, 130, 7224-7225.

14 H. Liu, S. Xu, Z. He, A. Deng and J.-J. Zhu, Anal. Chem., 2013, 85, 3385-3392.

15 C. Ding, S. Wei and H. Liu, Chem.-Eur. J., 2012, 18, 72637268.

16 H.-W. Shi, M.-S. Wu, Y. Du, J.-J. Xu and H.-Y. Chen, Biosens. Bioelectron., 2014, 55, 459-463.

17 A. G. Gehring, C. G. Crawford, R. S. Mazenko, L. J. Van Houten and J. D. Brewster, J. Immunol. Methods, 1996, 195, 15-25.

18 S. M. Radke and E. C. Alocilja, Biosens. Bioelectron., 2005, 20, 1662-1667.

19 K. Dill, L. H. Stanker and C. R. Young, J. Biochem. Biophys. Methods, 1999, 41, 61-67.

20 M. Hnaiein, W. Hassen, A. Abdelghani, C. Fournier-Wirth, J. Coste, F. Bessueille, D. Leonard and N. Jaffrezic-Renault, Electrochem. Commun., 2008, 10, 1152-1154.

21 D. Sun, J. Lu, Z. Chen, Y. Yu and M. Mo, Anal. Chim. Acta, 2015, 885, 166-173.

22 M. S. Artiles, C. S. Rout and T. S. Fisher, Adv. Drug Delivery Rev., 2011, 63, 1352-1360.

23 A. Yadegari, M. Omidi, M. Choolaei, F. Haghiralsadat and F. Yazdian, Procedia Eng., 2014, 87, 967-970.

24 M. Omidi, A. Fathinia, M. Farahani, Z. Niknam, A. Yadegari, M. Hashemi, H. Jazayeri, H. Zali, M. Zahedinik and L. Tayebi, Advanced 2D Materials, 2016, pp. 433-471.

25 G. Yang, J. Cao, L. Li, R. K. Rana and J.-J. Zhu, Carbon, 2013, 51, 124-133.
26 P. Sharma, S. K. Tuteja, V. Bhalla, G. Shekhawat, V. P. Dravid and C. R. Suri, Biosens. Bioelectron., 2013, 39, 99-105.

27 X. Luo, A. Morrin, A. J. Killard and M. R. Smyth, Electroanalysis, 2006, 18, 319-326.

28 W. Hong, H. Bai, Y. Xu, Z. Yao, Z. Gu and G. Shi, J. Phys. Chem. C, 2010, 114, 1822-1826.

29 K.-J. Huang, D.-J. Niu, J.-Y. Sun and J.-J. Zhu, J. Electroanal. Chem., 2011, 656, 72-77.

30 S. M. Pulukuri, C. S. Gondi, S. S. Lakka, A. Jutla, N. Estes, M. Gujrati and J. S. Rao, J. Biol. Chem., 2005, 280, 3652936540 .

31 A. Roth, D. C. Drummond, F. Conrad, M. E. Hayes, D. B. Kirpotin, C. C. Benz, J. D. Marks and B. Liu, Mol. Cancer Ther., 2007, 6, 2737-2746.

32 D. Carrión-Salip, C. Panosa, J. A. Menendez, T. Puig, G. Oliveras, A. Pandiella, R. De Llorens and A. Massaguer, Int. J. Oncol., 2012, 41, 1128-1138.

33 M. Hashemi, A. Yadegari, G. Yazdanpanah, S. Jabbehdari, M. Omidi and L. Tayebi, RSC Adv., 2016, 6, 74072-74084.

34 Q. Mu, G. Su, L. Li, B. O. Gilbertson, L. H. Yu, Q. Zhang, Y.-P. Sun and B. Yan, ACS Appl. Mater. Interfaces, 2012, 4, 2259-2266.

35 J. Zhang, J. Lei, R. Pan, C. Leng, Z. Hu and H. Ju, Chem. Commun., 2011, 47, 668-670.

36 M. Hashemi, A. Yadegari, G. Yazdanpanah, M. Omidi, S. Jabbehdari, F. Haghiralsadat, F. Yazdian and L. Tayebi, Biotechnol. Appl. Biochem., 2016, DOI: 10.1002/bab.1487.

37 M. Omidi, G. Amoabediny, F. Yazdian and M. Habibi-Rezaei, EPL, 2015, 109, 18005. 